\title{
Effects of bromide on the formation of THMs and HAAs
}

\author{
E.E. Chang ${ }^{a, *}$, Y.P. Lin ${ }^{b}$, P.C. Chiang ${ }^{b}$ \\ a Department of Biochemistry, Taipei Medical College, 250 Wu-Hsing Street, Taipei, 105 Taiwan, ROC \\ ${ }^{\mathrm{b}}$ Graduate Institute of Environmental Engineering, National Taiwan University, Taipei, Taiwan, ROC
}

Received 12 April 2000; accepted 19 June 2000

\begin{abstract}
The role of bromide in the formation and speciation of disinfection by-products (DBPs) during chlorination was investigated. The molar ratio of applied chlorine to bromide is an important factor in the formation and speciation of trihalomethanes (THMs) and halogenacetic acids (HAAs). A good relationship exists between the molar fractions of THMs and the bromide incorporation factor. The halogen substitution ability of $\mathrm{HOBr}$ and $\mathrm{HOCl}$ during the formation of THMs and HAAs can be determined based on probability theory. The formation of HAAs, and their respective concentrations, can also be estimated through use of the developed model. (c) 2001 Elsevier Science Ltd. All rights reserved.
\end{abstract}

Keywords: Bromide; Chlorination; Trihalomethanes; Haloacetic acids

\section{Introduction}

In water treatment plants, hypobromous acid $(\mathrm{HOBr})$ and hypobromite are generated due to the reaction of chlorine and bromide (Wong and Davidson, 1977). HOBr is more powerful than hydrochlorous acid (Morris, 1978) and its role in the formation of disinfection by-products (DBPs) is analogous to that of $\mathrm{HOCl}$. Symons et al. (1993) have indicated that HOBr reacts with natural organic matter $(\mathrm{NOM})$ faster than $\mathrm{HOCl}$, and the ratio of $\mathrm{HOBr} / \mathrm{HOCl}$ plays an important role in the formation of trihalomenthanes (THMs) and halogenacetic acids (HAAs) (Cowman and Singer, 1996). The bromide ion shifts the distribution of HAAs to more brominated species (Pourmoghaddas et al., 1993), including bromodichloromethane, dibromochloromethane, bromoform and brominated acetic acids; the distribution of chlorinated DBPs and brominated DBPs

\footnotetext{
${ }^{*}$ Corresponding author. Tel.: +886-22736-9236; fax: +88622736-9236.

E-mail address: eechang@tmc.edu.tw (E.E. Chang).
}

is affected by the ratios of $\mathrm{HOCl} / \mathrm{Br}^{-}$(Rebhun et al., 1990), $\mathrm{Br}^{-} / \mathrm{NOM}$ and $\mathrm{Br}^{-} /$free chlorine (Shukairy et al., 1995). The formation of bromate in the presence of ozone also presents a problem in the light of the recent D/DBP rule on the maximum permissible contaminant level of bromate $(0.01 \mathrm{mg} / \mathrm{l})$ (Federal Register, 1998).

The purpose of this study was to systematically investigate the role of bromide on the formation and species distribution of THMs and HAAs. Specifically, a model based on probability theory, developed by others, was used to determine the relative reaction rates of $\mathrm{HOBr}$ and $\mathrm{HOCl}$ and to estimate the concentration of HAA species that could not be quantified.

\section{Materials and methods}

\subsection{Experiment design}

Water samples used in this study were directly collected without extraction from the source water of a local treatment plant in Taipei County. Water quality characteristics of the raw water were: dissolved organic 
carbon $(\mathrm{DOC})=1.5 \mathrm{mg} / \mathrm{l}$ and $\mathrm{UV}_{254}=0.047$. Chlorination was performed in water buffered with $0.05 \mathrm{M}$ phosphate at $\mathrm{pH}$ 7.0. Stock solutions of sodium hypochlorite were standardized by the iodometric method (APHA, 1995). A vial containing $100 \mathrm{ml}$ filtered water $(0.45 \mu \mathrm{m})$ was used for each kinetic experiment. The vial was placed in an incubator $\left(25^{\circ} \mathrm{C}\right)$, and the reaction was quenched after $24 \mathrm{~h}$ with an $\mathrm{Na}_{2} \mathrm{SO}_{3}$ solution. Five chlorine concentrations, 2-6 mg/l $(0.028-0.085 \mathrm{mM})$, were used. For each chlorine dosage, six bromide concentrations, $0.1-4 \mathrm{mg} / \mathrm{l}(0.001-0.050 \mathrm{mM})$, were added to form a five by six matrix.

\subsection{THMs and HAAs: analytical methods}

For THM analysis, the sample was first extracted with $n$-pentane, and the extract was then analyzed using a gas chromatograph (HP 5180-II) with a fused silica capillary column (Restek Mtx-5, $30 \mathrm{~m} \times 0.28 \mathrm{~mm}$ ID and $1.0 \mu \mathrm{m}$ film thickness) and an electronic capture detector. A micro-extraction procedure (extracting with methyl-tert-butyl ether and esterfied with diazomethane) was used to analyze $\mathrm{HAA}_{5}$. The esterfied extract was analyzed using the same gas chromatograph. Supelco standard solutions were prepared for calibrating four THM compounds and six HAA compounds. All the detailed analyses followed the QA/QC programs set forth in Standard Methods (APHA, 1995) including detection limits, internal standard, surrogate standard and preservative agents for DBPs.

\section{Results and discussion}

\subsection{THM and HAA formation}

The formation of THM in the source water spiked with bromide is shown in Fig. 1. In general, total THM concentration increases slightly with increasing bromide concentration; a slight decrease in total THM with higher $\mathrm{Br}^{-}$concentration is noted at lower chlorine dosage. The patterns of the four THM species with increased $\mathrm{Br}^{-}$concentrations are as follows: $\mathrm{CHCl}_{3}$ and $\mathrm{CHCl}_{2} \mathrm{Br}$ decrease continuously; $\mathrm{CHBr}_{2} \mathrm{Cl}$ increases initially and then decreases, with the peaks occurring at bromide concentrations of $0.0038-0.0063 \mathrm{mM}(0.3-0.5$ $\mathrm{mg} / \mathrm{l}) ; \mathrm{CHBr}_{3}$ increases continuously. The patterns are similar for the different applied chlorine dosages studied in this paper. THM speciation gradually shifts from chlorinated species to mixed bromochloro species to brominated species with increasing bromide concentration. Even at the lowest bromide concentration used $(0.0013 \mathrm{mM})$, mixed bromochloro and brominated THM species are produced.

The formation of five species of HAAs is shown in Fig. 2. Analogous to the formation of THM, HAA

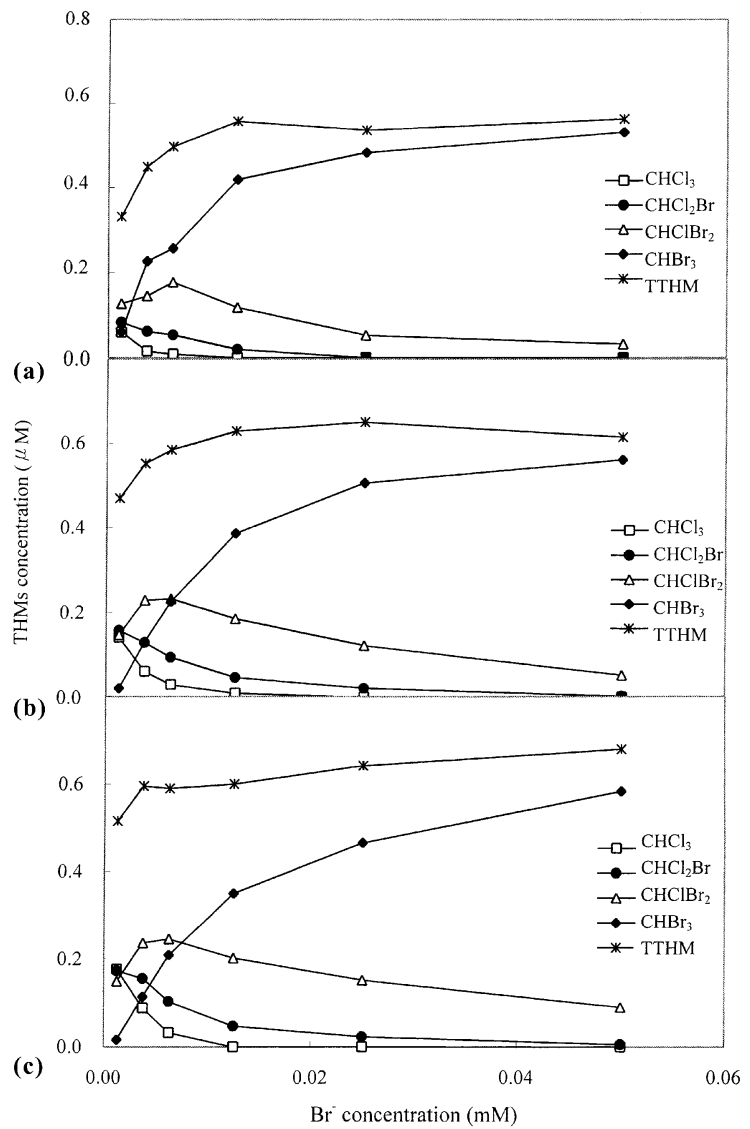

Fig. 1. THM formation as a function of bromide concentration under various $\mathrm{Cl}_{2}$ concentrations. (a) $\mathrm{Cl}_{2}=2.0 \mathrm{mg} / \mathrm{l}(0.028$ $\mathrm{mM})$, (b) $\mathrm{Cl}_{2}=4.0 \mathrm{mg} / \mathrm{l}(0.056 \mathrm{mM}),(\mathrm{c}) \mathrm{Cl}_{2}=6.0 \mathrm{mg} / \mathrm{l}(0.085$ $\mathrm{mM})$.

speciation gradually shifts to brominated species with increasing bromide concentration. The formation of $\mathrm{HAA}_{5}$ at the three applied chlorine dosages is different. For instance, at the lowest chlorine dosage used $(0.028$ $\mathrm{mM}$ ), no chlorinated species was observed. Instead, dibromoacetic acid (DBAA) increases with increased bromide concentration, whereas bromochloroacetic acid (BCAA) first increases and then decreases. As the chlorine dosage increases to $0.056 \mathrm{mM}$, four HAA species are found and the chlorinated species are gradually replaced by mixed or brominated species with increasing bromide concentration. The variation of total $\mathrm{HAA}_{5}$ at this chlorine dosage with various bromide concentrations is not dramatic, due to the balance between the decreased chlorinated species and the increased detectable brominated species, DBAA. It is noted that the formation of both dibromochloroacetic acid $\left(\mathrm{Br}_{2} \mathrm{ClAA}\right)$ and tribromoacetic acid (TBAA) is expected at higher bromide/chlorine ratios. Unfortunately, the standards of three HAA species, i.e., bromodichloroacetic acid $\left(\mathrm{BrCl}_{2} \mathrm{AA}\right), \mathrm{Br}_{2} \mathrm{ClAA}$ and TBAA, are not commercially 


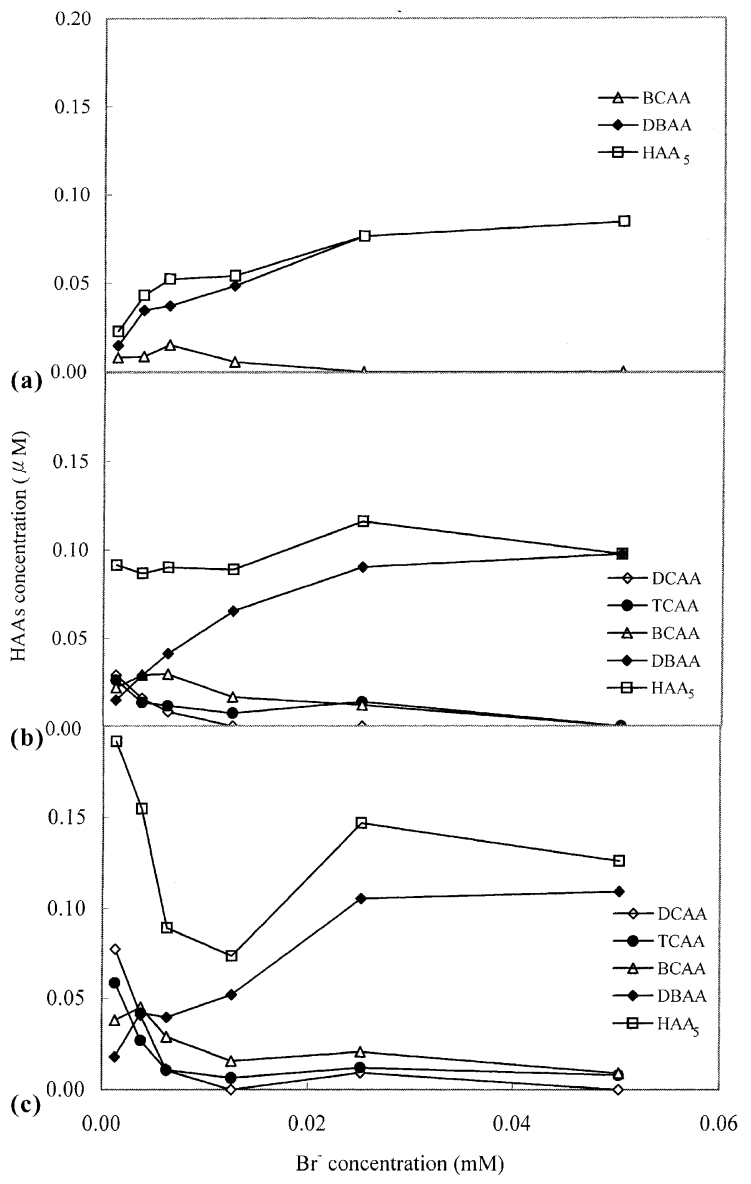

Fig. 2. HAA formation as a function of bromide concentration under various $\mathrm{Cl}_{2}$ concentrations. (a) $\mathrm{Cl}_{2}=2.0 \mathrm{mg} / \mathrm{l}(0.028$ $\mathrm{mM})$, (b) $\mathrm{Cl}_{2}=4.0 \mathrm{mg} / \mathrm{l}(0.056 \mathrm{mM})$, (c) $\mathrm{Cl}_{2}=6.0 \mathrm{mg} / \mathrm{l}(0.085$ $\mathrm{mM})$.

available resulting in inability to detect these compounds.

At the highest chlorine dosage used $(0.085 \mathrm{mM})$, the concentration of $\mathrm{HAA}_{5}$ decreases and then increases with the increasing bromide concentration. The initial decrease in $\mathrm{HAA}_{5}$ concentration may result from the non-detection of $\mathrm{BrCl}_{2} \mathrm{AA}, \mathrm{Br}_{2} \mathrm{ClAA}$ and TBAA. The concentrations of the three species should be greater than those in lower chlorine dosage conditions because of higher concentrations of $\mathrm{HOBr}$ generated from the reaction of chlorine and bromide. As bromide concentration further increases, DBAA, as well as two undetected $\mathrm{Br}_{2} \mathrm{ClAAs}$ and TBAAs, increases gradually with the corresponding decrease of other chlorinated species, resulting in an overall increase in observed $\mathrm{HAA}_{5}$ and other undetectable bromo-dominant species.

The molar ratio of applied chlorine to bromide is an important factor to be considered while examining DBP formation and speciation. The formation of THMs and
HAAs as a function of the $\mathrm{Cl}_{2} / \mathrm{Br}^{-}$ratio is shown in Fig. 3. As the $\mathrm{Cl}_{2} / \mathrm{Br}^{-}$molar ratio increases, the concentrations of $\mathrm{CHClBr}_{2}, \mathrm{CHCl}_{2} \mathrm{Br}$ and $\mathrm{CHCl}_{3}$ increase. $\mathrm{CHBr}_{3}$ is the only species that decreases with increasing $\mathrm{Cl}_{2} / \mathrm{Br}^{-}$. At $\mathrm{Cl}_{2} / \mathrm{Br}^{-}=7, \mathrm{CHBr}_{3}$ is about $50 \%$ of total THMs. At $\mathrm{Cl}_{2} / \mathrm{Br}^{-}=9$, the sum of $\mathrm{CHBr}_{3}$ and $\mathrm{CHClBr}_{2}$ is $79 \%$ of total THMs. Similar results are also reported by Rebhun et al. (1990), or $40 \%$ and $90 \%$ for $\mathrm{Cl}_{2} / \mathrm{Br}^{-}=7$ and 10, respectively. As for HAAs, the formation of BCAA and, to a lesser extent, DCAA and TCAA increases with increasing $\mathrm{Cl}_{2} / \mathrm{Br}^{-}$while DBAA concentration decreases.

\subsection{Bromine incorporation}

Gould et al. (1983) introduce bromine incorporation factor $n$, a dimensionless factor, to evaluate THM speciation, in which $n$ is the molar amount of bromine in the THMs $\left(\mathrm{CHBrCl}_{2}+2 \mathrm{CHClBr}_{2}+3 \mathrm{CHBr}_{3}\right)$ divided by the molar TTHM concentration:

$n=\frac{\mathrm{CHBrCl}_{2}+2 \mathrm{CHClBr}_{2}+3 \mathrm{CHBr}_{3}}{\mathrm{TTHM}} \quad(0 \leqslant n \leqslant 3)$

The value of $n$ varies between 0 and 3, with 0 corresponding to the formation of only $\mathrm{CHCl}_{3}$ and 3 to that of $\mathrm{CHBr}_{3}$. In order to investigate the relationship

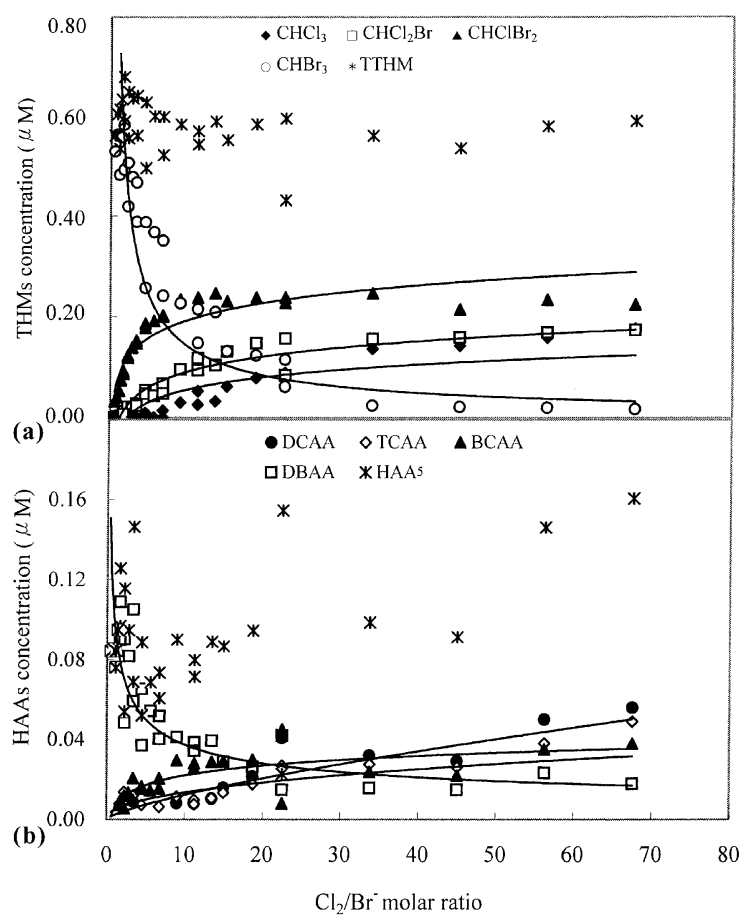

Fig. 3. DBP formation as a function of $\mathrm{Cl}_{2} / \mathrm{Br}^{-}$molar ratio. (a) THMs, (b) HAAs. 


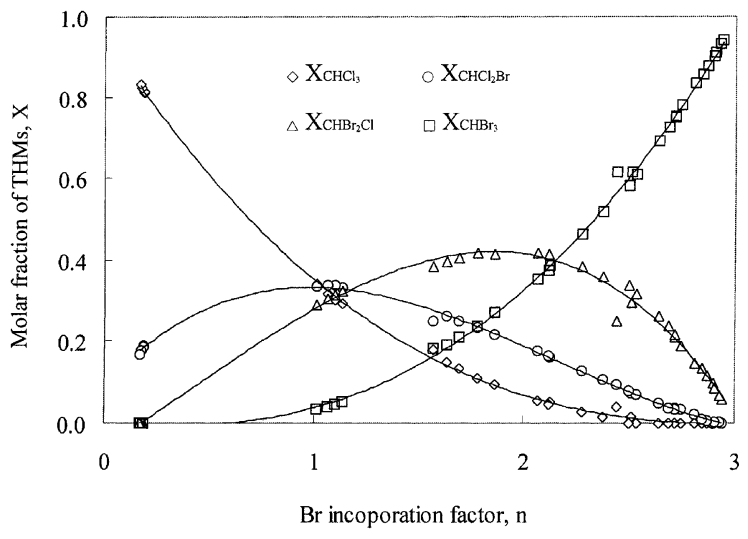

Fig. 4. Molar fraction of each THM species vs. bromine incorporation factor.

between the formation of each THM species and bromine incorporation factor, the molar fraction of each THM species is plotted vs. bromine incorporation factor as shown in Fig. 4.

Each molar fraction can be expressed by a thirdorder polynomial via regression.

$$
\begin{aligned}
& X_{\mathrm{CHCl}_{3}}=-0.018 n^{3}+0.216 n^{2}-0.82 n+1 ; \\
& R^{2}=0.994
\end{aligned}
$$

$$
\begin{aligned}
& X_{\mathrm{CHCl}_{2} \mathrm{Br}}=0.055 n^{3}-0.355 n^{2}+0.538 n+0.096 \\
& R^{2}=0.998
\end{aligned}
$$

$X_{\mathrm{CHClBr}_{2}}=-0.054 n^{3}+0.062 n^{2}+0.332 n-0.061 ;$

$$
R^{2}=0.986
$$

$$
X_{\mathrm{CHBr}_{3}}=0.018 n^{3}+0.077 n^{2}-0.06 n ; \quad R^{2}=0.987
$$

The peak value locations of $X_{\mathrm{CHCl}_{2} \mathrm{Br}}$ and $X_{\mathrm{CHClBr}_{2}}$ can be determined as:

$\frac{\mathrm{d} X}{\mathrm{~d} n}=0$

The peak value of each molar fraction occurs at $n=0$ for $X_{\mathrm{CHCl}_{3}}, n=1.0$ for $X_{\mathrm{CHCl}_{2} \mathrm{Br}}, n=1.85$ for $X_{\mathrm{CHClBr}_{2}}$ and $n=3.0$ for $X_{\mathrm{CHBr}_{3}}$. The results indicate that the peak molar fraction of each THM species can be determined by the incorporated bromine concentration.

\subsection{THM and HAA speciation and concentration based on probability theory}

From the results presented above, the speciation of THM and HAA is related to the reactivities of $\mathrm{HOCl}$ and $\mathrm{HOBr}$ in the halogen substitution reactions with NOM. Analogous to the development of Cowman and Singer (1996) for HAA speciation with the assumption that the reactivity of $\mathrm{HOBr}$ is set $\gamma$ times stronger than that of $\mathrm{HOCl}$, the same approach is used for THM speciation as follows:

$$
\begin{aligned}
X_{\mathrm{CHCl}_{3}}= & 1 /\left\{1+3 \gamma \frac{[\mathrm{HOBr}]}{[\mathrm{HOCl}]}+3 \gamma^{2}\left(\frac{[\mathrm{HOBr}]}{[\mathrm{HOCl}]}\right)^{2}\right. \\
& \left.+\gamma^{3}\left(\frac{[\mathrm{HOBr}]}{[\mathrm{HOCl}]}\right)^{3}\right\}
\end{aligned}
$$

$$
\begin{aligned}
X_{\mathrm{CHCl}_{2} \mathrm{Br}}= & \left\{3 \gamma \frac{[\mathrm{HOBr}]}{[\mathrm{HOCl}]}\right\} /\left\{1+3 \gamma \frac{[\mathrm{HOBr}]}{[\mathrm{HOCl}]}\right. \\
& \left.+3 \gamma^{2}\left(\frac{[\mathrm{HOBr}]}{[\mathrm{HOCl}]}\right)^{2}+\gamma^{3}\left(\frac{[\mathrm{HOBr}]}{[\mathrm{HOCl}]}\right)^{3}\right\} \\
X_{\mathrm{CHClBr}_{2}}= & \left\{3 \gamma^{2}\left(\frac{[\mathrm{HOBr}]}{[\mathrm{HOCl}]}\right)^{2}\right\} /\left\{1+3 \gamma \frac{[\mathrm{HOBr}]}{[\mathrm{HOCl}]}\right. \\
& \left.+3 \gamma^{2}\left(\frac{[\mathrm{HOBr}]}{[\mathrm{HOCl}]}\right)^{2}+\gamma^{3}\left(\frac{[\mathrm{HOBr}]}{[\mathrm{HOCl}]}\right)^{3}\right\}
\end{aligned}
$$

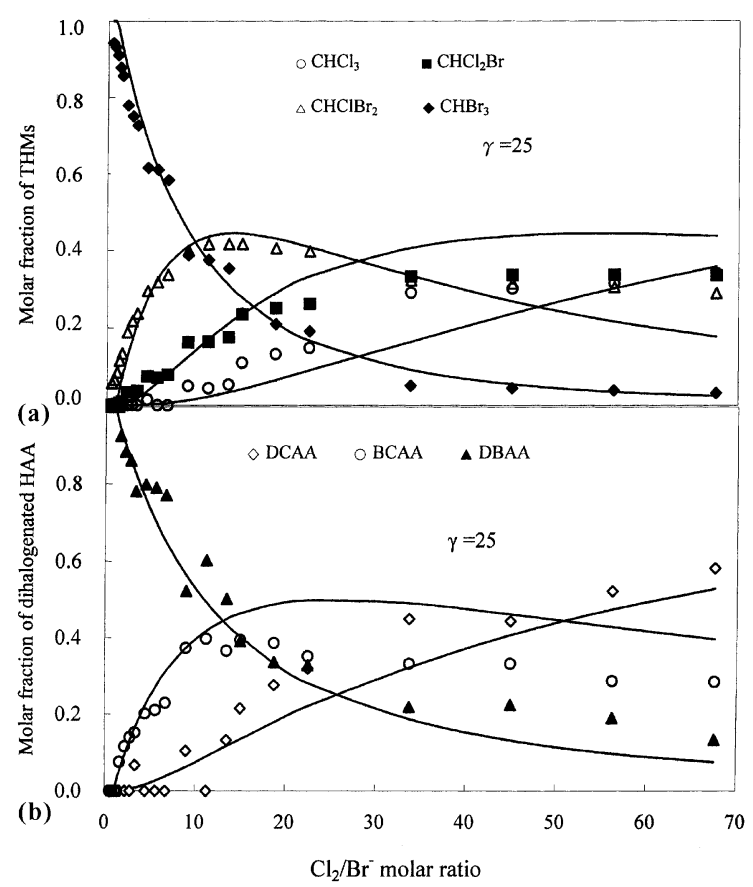

Fig. 5. Modeling the molar fraction by probability theory. (a) THMs, (b) dihalogenated HAAs. 
Table 1

Comparison of experimental conditions

\begin{tabular}{llllll}
\hline Source & $\mathrm{pH}$ & $\begin{array}{l}\text { Temperature } \\
\left({ }^{\circ} \mathrm{C}\right)\end{array}$ & $\mathrm{NOM}(\mathrm{mg} / \mathrm{l})$ & $\mathrm{Cl}_{2}(\mathrm{mM})$ & $\mathrm{Br}^{-}(\mu \mathrm{M})$ \\
\hline $\begin{array}{l}\text { Subject study } \\
\text { Cowman and }\end{array}$ & 7 & 25 & 1.5 (DOC) & $0.028-0.085$ & $1.3-50.0$ \\
$\begin{array}{l}\text { Singer (1996) } \\
\begin{array}{l}\text { Nokes et al. } \\
(1999)\end{array}\end{array}$ & $6.9-8.4$ & $13-23$ & $4.0(\mathrm{TOC})$ & 0.113 & $0-25.0$ \\
\hline
\end{tabular}

Table 2

Simulation of the formation of trihalogenated HAA species

\begin{tabular}{cccccc}
\hline $\mathrm{Cl}_{2} / \mathrm{Br}$ (molar ratio) & $\begin{array}{l}\mathrm{TCAA}^{*} \\
(\mu \mathrm{M})\end{array}$ & $\begin{array}{l}\mathrm{BrCl}_{2} \mathrm{AA} \\
(\mu \mathrm{M})\end{array}$ & $\begin{array}{l}\mathrm{Br}_{2} \mathrm{ClAA} \\
(\mu \mathrm{M})\end{array}$ & $\begin{array}{l}\text { TBAA } \\
(\mu \mathrm{M})\end{array}$ & Total trihalogenated HAA $(\mu \mathrm{M})$ \\
\hline 6.8 & 6.3 & 82 & 358 & 519 & 966 \\
9.0 & 11.4 & 107 & 339 & 356 & 814 \\
11.3 & 7.7 & 56 & 138 & 113 & 314 \\
13.5 & 10.6 & 64 & 130 & 88 & 293 \\
15.0 & 13.3 & 72 & 130 & 78 & 293 \\
18.8 & 17.5 & 75 & 107 & 51 & 250 \\
22.5 & 26.9 & 95 & 111 & 44 & 277 \\
33.8 & 27.4 & 66 & 53 & 14 & 160 \\
45.1 & 26.1 & 47 & 28 & 6 & 107 \\
56.4 & 47.1 & 67 & 32 & 5 & 151 \\
67.6 & 58.6 & 70 & 28 & 4 & 161 \\
\hline
\end{tabular}

${ }^{*}$ Experimental values.

$$
\begin{aligned}
X_{\mathrm{CHBr}_{3}}= & \left\{\gamma^{3}\left(\frac{[\mathrm{HOBr}]}{[\mathrm{HOCl}]}\right)^{3}\right\} /\left\{1+3 \gamma \frac{[\mathrm{HOBr}]}{[\mathrm{HOCl}]}\right. \\
& \left.+3 \gamma^{2}\left(\frac{[\mathrm{HOBr}]}{[\mathrm{HOCl}]}\right)^{2}+\gamma^{3}\left(\frac{[\mathrm{HOBr}]}{[\mathrm{HOCl}]}\right)^{3}\right\}
\end{aligned}
$$

The experimental data of THM and dihalogenated HAAs are used for the best-fitting values of $\gamma$, as shown in Fig. 5. For THM, the best-fitting value of $\gamma$ is 25, which means that $\mathrm{HOBr}$ is 25 times stronger than $\mathrm{HOCl}$ in halogen substitution for THM formation. For dihalogenated HAA, the best fitting value of $\gamma$ is again 25 . The $\gamma$ values for THM formation and HAA formation, reported by Bird (1979) and Cowman and Singer (1996), are 20 and 10, respectively. Nokes et al. (1999) also reported that the relative rate constant ratio of bromination to chlorination has an approximate value of 9, determined by a three-step formation model of THM. The deviation among the $\gamma$ values reported by these investigators may be caused by the different experimental parameters, i.e., $\mathrm{pH}$, chlorine dosages, temperature and the nature and concentration of NOM. Table 1 presents the comparison of experimental conditions.

The undetectable HAA species can be determined by the assumption that the halogen substitution abilities of $\mathrm{HOBr}$ and $\mathrm{HOCl}$ are the same among monohalogenated, dihalogenated and trihalogenated groups. In the case of this study, the $\gamma$ value of 25 can be used to determine the total molar concentration of trihalogenated HAAs from the given TCAA molar concentration. The results are shown in Table 2. Unfortunately, the formation of monohalogenated HAA cannot be simulated because of undetectable levels of bromoacetic acid (MBAA).

\section{Conclusions}

The molar ratio of applied chlorine to bromide dosage is an important factor in examining DBP formation and speciation. For instance, as $\mathrm{Cl}_{2} / \mathrm{Br}^{-}$molar ratio increases, the concentrations of $\mathrm{CHClBr}_{2}, \mathrm{CHCl}_{2} \mathrm{Br}$ and $\mathrm{CHCl}_{3}$ increase. $\mathrm{CHBr}_{3}$ is the only species that decreases with increasing $\mathrm{Cl}_{2} / \mathrm{Br}^{-}$ratios. As for HAAs, the formation of BCAA and, to a lesser extent, DCAA and TCAA, increases with increasing $\mathrm{Cl}_{2} / \mathrm{Br}^{-}$while DBAA formation decreases. Each molar fraction of THM and its peak value can be expressed by a third-order polynomial in terms of the bromide incorporation factor. The halogen substitution ability of $\mathrm{HOBr}$ and $\mathrm{HOCl}$ during the formation of THMs and HAAs can be determined based on probability theory. In both halogen substitution for THM and dihalogenated HAA formation, $\mathrm{HOBr}$ is 25 times stronger than $\mathrm{HOCl}$. Undetectable HAA species can be determined through use of the developed model based on the halogen substitution ability of $\mathrm{HOBr}$ and $\mathrm{HOCl}$. 


\section{References}

APHA, 1995. Standard Methods for the Examination of Water and Wastewater, 19th ed. Am. Pub. Health Assoc., Washington, DC

Bird, J.C., 1979. The effect of bromide on trihalomethane formation. Masters' Thesis, University of Tennessee, Knoxville, TN.

Cowman, G.A., Singer, P.C., 1996. Effect of bromide ion on haloacetic acid speciation resulting from chlorination and chloramination of aquatic humic substances. Environ. Sci. Technol. 30 (1), 16-24.

Federal Register, 1998. National Primary Drinking Water Regulations: Disinfection and Disinfection Byproducts: Final Rule, 40CFR Parts 9, 141 and 142, December 16.

Gould, J.P., Fitchorn, L.E., Urheim, E., 1983. Formation of brominated trihalomethane: extent and kinetics. In: Jolley, R.L. (Ed.), Water Chlorination: Environmental Impact and Health Effects, vol. 4. Ann Arbor Science, Ann Arbor, MI.

Morris, J.C., 1978. The chemistry of aqueous chlorine in relation to water chlorination. In: Jolley, R.L. (Ed.), Water
Chlorination: Environmental Impact and Health Effects, vol. 3. Ann Arbor Science, Ann Arbor, MI.

Nokes, C.J., Fenton, E., Randall, C.J, 1999. Modelling the formation of brominated trihalomethanes in chlorinated drinking waters. Water Res. 33 (17), 3557-3568.

Pourmoghaddas, H., Stevens, A.A., Kinman, R.N., Dressman, R.C., Moore, L.A., Ireland, J.C., 1993. J. Am. Water Works Assoc. 85 (1), 82-87.

Rebhun, M., Heller-Grossman, L., Manka, J., Kimel, D., Limoni, B., 1990. Trihalomethane formation and distribution in bromide-rich and ammonia-containing lake water. In: Water Chlorination: Environmental Impact and Health Effects, vol. 6. Lewis, Chelsea, MI, pp. 665-680.

Shukairy, H.M., Miltner, R.J., Summers, R.S., 1995. Bromide's effect on DBP formation, speciation, and control: part 2, biotreatment. J. Am. Water Works Assoc. 87 (10), 71-82.

Symons, J.M., Kranser, S.W., Simms, L.A., Sclimenti, M., 1993. Measurement of THM and precursor concentrations revisited: the effect of bromide ion. J. Am. Water Works Assoc. 85 (1), 51-62.

Wong, G.T.F., Davidson, J.A., 1977. The fate of chlorine in seawater. Water Res. 11 (11), 971-978. 